Volunteering to Be Taxed: Business

Improvement Districts and the Extra-Governmental Provision of Public Safety

\author{
Leah Brooks \\ McGill University
}

May 2006

Prodigious thanks to my two advisors Janet Currie and Jean-Laurent Rosenthal. I am also appreciative for the help from UCLA faculty past and present: Enrico Moretti, Jeffrey Grogger, Sandra Black, Kathleen McGarry and Paul Ong. For econometric advice, many thanks to Jin Hahn and Moshe Buchinsky. I am also appreciative for the help of fellow students in the History and Applied proseminars at UCLA and for the advice of an anonymous referee. Particular thanks also go to the city and BID employees who were kind, patient and helpful with my repeated questions. Finally, I am very grateful for help from UCLA's statistical computing consultants, who provide elegant solutions to tricky problems. 


\begin{abstract}
When the median voter's preference sets the level of local public goods, some voters are left unsatisfied. Is there an institution by which subsets of voters can resolve the collective action problem and increase the local provision of public goods? If so, what are the consequences? In response to problems such as crime and vandalism, neighborhood property owners have established Business Improvement Districts (BIDs) to provide local public goods. When a BID is approved by a majority of property owners in a neighborhood, state law makes contributions to the BID budget mandatory. This resolution of the neighborhood's collective action problem reduces crime - BIDs in the city of Los Angeles are robustly associated with crime declines of 5 to 9 percent. Indeed, crime falls regardless of estimation technique: fixed effects; comparing BIDs to neighborhoods that considered, but did not adopt, BIDs; using propensity score matching; and comparing BIDs to their neighbors. Strikingly, these declines are purchased cheaply. Attributing all BID expenditure to violent crime reduction, and thus ignoring the impact of BID expenditure on many quality-of-life crimes, BIDs spend $\$ 21,000$ to avert one violent crime. This higher bound estimate is substantially lower than the $\$ 57,000$ social cost of a violent crime.
\end{abstract}

\title{
Leah Brooks
}

Department of Economics

McGill University

855 Sherbrooke St West

439 Leacock Hall

Montreal, QC h3a 2t7

CANADA

leah.brooks@mcgill.ca 
Because free riding prevails, large groups fail to provide even those public goods which each individual desires. The standard solution for such a collective action problem is for the government to compel taxation, and provide the public good for everyone. But what if this governmentally provided level of public goods is unacceptably low for some groups? Are there mechanisms which allow for the extra-governmental provision of public goods? Theory suggests that decentralized provision should be more efficient when public goods are local - is this true?

Within a city, neighborhoods may be dissatisfied with the municipal government's level of provision of local public goods. But even if a property owner is displeased with the level of municipally provided public goods, such as security or maintenance, any desire to invest in his troubled neighborhood is thwarted by his reluctance to do so alone. To solve the problem of collective action in the provision of public goods such as safety and cleanliness, a neighborhood institution called a Business Improvement District (BID) has become popular. ${ }^{1}$ In a BID, property owners volunteer for additional taxation, binding upon all members, in order to provide neighborhood-wide services, predominantly cleaning, security, and maintenance. What makes this extraordinary form of collective action possible is the proviso that once a majority of commercial property owners vote to establish the BID, all commercial property owners in the district are legally bound to pay the tax. Thus BIDs are extra-governmental providers of public goods.

Economists have long been interested in the causes of extra-governmental provision of public goods, the distribution of the providers of those goods, and the consequences of adopting extra-governmental provision (Demsetz, 1970; Epple and Romano, 1996; Ostrom, 1990). In fact, previous work has looked theoretically at BIDs in this regard (Helsley and Strange 1998, Helsley and Strange 1999), and this project investigates these issues empirically at an extremely local level. In addition, economists have studied the efficient level for the provision of public goods (Alesina,

\footnotetext{
${ }^{1}$ In the 1990s, BIDs formed in New York, Philadelphia, Baltimore, Washington, D.C., Charlotte, Atlanta, Pittsburgh, St. Louis, Denver, Los Angeles, San Diego, Portland, Seattle and other cities. A 1999 survey found 404 BIDs in the United States, and six of the ten largest American metropolitan areas have cities with BIDs (Houston, Jr., 2003; Mitchell, 2001). BIDs are also present in Canada, the United Kingdom, South Africa, Australia and New Zealand.
} 
et al., 2004; Tiebout, 1956; Konrad, 1994) but not with the fine grain detail offered here. To municipal officials, BIDs may seem like a mechanism for near-free funding of municipal improvement, in exchange for a small cession of sovereignty. They may also view BIDs' activities as a welcome alternative to the dubiously-reviewed performance of government sponsored and directed revitalization initiatives, such as Tax Increment Financing Districts, Enterprise Communities, Empowerment Zones, and local redevelopment zones (see Dye and Merriman (2000) and the review in Peters and Fisher (2002)).

Crime is among the most serious of the neighborhood ills which BIDs and policy makers tackle. In commercial neighborhoods, crime keeps customers away and lowers property values. Not surprisingly, one of the major stated and budgetary goals of BIDs is reducing crime. This paper evaluates how successful Los Angeles city BIDs are at this task; Los Angeles makes a good test case because of a major law change with respect to BIDs in 1994. The use of this law change differentiates this analysis from that of Calanog (2004) and Hoyt (2004), who examines the impact of BID expenditure on crime deterrence and displacement in the city of Philadelphia. More generally, previous research has shown that urban crime causes central city residents to flee to outlying cities (Cullen and Levitt, 1999), so BIDs' success has an impact beyond their immediate neighborhoods.

This evaluation relies upon a novel dataset I constructed that combines neighborhood level reported crimes and arrests from the Los Angeles Police Department (LAPD) over a 13 year period with information on properties from the Los Angeles County Assessor. In addition, the dataset contains location, expenditure and adoption timing information I collected on BIDs from city council files and interviews. All these data are at a neighborhood level, where the median neighborhood size is 0.8 square kilometers.

In other work, I show that the adoption of a BID is a neighborhood choice and not an assignment (Brooks, 2005). BIDs are therefore not located randomly across the city, and this 
presents difficulties in estimating the causal influence of BIDs on crime. Because theory indicates that BID adoption is determined by long-standing problems, such as high levels of crime or badly decayed infrastructure, neighborhood fixed effects capture key BID-forming attributes. To improve on the fixed effects approach and control for time-varying factors underlying BID formation, such as changes in neighborhood organization, I compare BIDs to neighborhoods that seriously considered adopting BIDs. This controls non-parametrically for the desire to adopt a BID. I buttress these estimates with two other types of matching: by a propensity score based on pre-BID conditions and by proximity. Comparing BIDs with their neighbors, I am able to rule out the hypothesis that BID crime decline is attributable solely to crime shifting.

Across estimation procedures, BIDs are associated with large declines of at least 5 to 9 percent in total crime, with the bulk of this decline attributable to decreases in serious crime. ${ }^{2}$ These serious crimes include the most frequently occurring - e.g., auto theft - and the most grave murder and rape. However, unless we understand how BIDs reduce crime, these results are hard to interpret. I show that while BIDs reduce crime, they are only modestly associated with changes in police enforcement. Thus, BIDs' success is not achieved at the cost of lowered police attentiveness to other areas.

Using BID expenditures on security, I find that BIDs reduce crime very cheaply. One of out every seven crimes a BID averts is a violent one; attributing BIDs’ entire security costs of $\$ 3,000$ per averted crime to the violent ones, BIDs are still a good social deal, compared to the social cost of $\$ 57,000$ per victim from the least costly violent crime $^{3}$, serious assault (Cohen et al., 2004). BID expenditure per averted violent crime $-\$ 21,000$ - is at the very low end of estimates of police cost per averted violent crime of $\$ 20,000$ to $\$ 86,000$, suggesting that BIDs are efficient providers of

\footnotetext{
${ }^{2}$ Here, "serious" crimes are the FBI's Part I index offenses. "Less serious" crimes are Part II offenses. Using average levels of crime in BIDs over the period, instead of the pre-BID averages, yields results of 6 to 13 percent.

${ }^{3}$ This estimate includes tangible and quality-of-life costs of crime, but includes neither the costs incurred by the criminal to the penal system, nor more indirect social costs.
} 
public safety. ${ }^{4}$ Supplementing municipal police provision at the neighborhood level, rather than lobbying for changes at the city level, lowers the cost of public safety and is a more efficient alternative for BID neighborhoods.

\section{What is a BID?}

I examine BIDs' resolution of the collective action problem using Los Angeles as a test case. Los Angeles is a particularly good analytical example because the city had no BID infrastructure and no BIDs at all prior to 1994, and many thereafter. In 1994 the California Legislature passed a law allowing for the taxation of property owners to fund neighborhood improvements ${ }^{5}$; previous legislation had allowed only for the taxation of merchants. As the residual claimants to the value of real estate, property owners have the most to gain from improvement, and were viewed as the most likely financiers, as well as those with the deepest pockets. Only after the passage of this 1994 law, and in response to demand from neighborhoods, did Los Angeles set up an administrative apparatus to perform the city's end of BID administration.

In order to establish a BID, property owners in a neighborhood decide upon a boundary, assessment schedule and budget for the district. They then attempt to convince their neighbors that they, too, should support the BID. Properties in BIDs may be assessed in any way commensurate with the benefits that property receives; usually the assessment is some combination of building square footage, lot square footage, and front footage. When property owners vote on the BID, they vote on the entire bundle of boundaries, assessments and expenditures for the 3 to 5 year life of the BID. If a majority of assessment-weighted votes are cast in favor of the BID, it is established and

\footnotetext{
${ }^{4}$ These figures come from combining Levitt's (2004) high and low instrumental variable estimates of per capita crime decline as a function of per capita police levels with 1995 data from the FBI's Uniform Crime Reports, and a high and low estimate of the cost of a police officer. Because the city of Los Angeles has such a strikingly low police presence, a similar calculation with data from the LAPD for 1995 yields smaller estimates of $\$ 8,000$ to $\$ 34,000$.

${ }^{5}$ This new law escapes the stringencies of California's Proposition 13 by calling the tax an assessment.
} 
taxes are mandatory for all owners within the district. The BID then functions as a not-for-profit corporation.

Los Angeles' 30 BIDs are shown in Figure 1, and have a mean BID adoption year of 1999. From this map, and from Table 1, it is clear that these BIDs are quite small. BIDs are usually much smaller than a square kilometer, and they make up less than two percent of the area of the city of Los Angeles. In terms of sales revenue, firms in BIDs accounted for about a fifth of 1999 retail sales revenue in the city of Los Angeles. ${ }^{6}$ The bottom half of the table details budgeted BID expenditures. In 2002, BIDs spent almost 19 million dollars. A third of that expenditure went to security, and the remaining funds went to a mix of marketing, cleaning, special projects and administration. The 19 BIDs that do spend money on security account for the vast majority of BID spending, and the median BID in this group spends a little over $\$ 200,000$ per year to combat crime, with a few BIDs spending a great deal more.

Compared to the hundreds of millions in federal monies spent on the Section 8 housing program or Community Development Block Grants, these numbers may seem small. However, when compared to city spending, BID expenditures are large local investments. The Downtown Center BID, the largest BID by expenditure, spends approximately \$1 million per square kilometer on security. ${ }^{7}$ It adds fully 25 percent to the $\$ 4.3$ million per square kilometer that the LAPD spends in that area (Los Angeles Police Department, Information Technology Division, 2003; City of Los Angeles, 2003). ${ }^{8}$ Outside the downtown areas, the figures can be even more striking: the Hollywood Entertainment District BID covers roughly three-quarters of a square kilometer and its \$1.4 million per square kilometer of security spending slightly exceeds LAPD expenditures of \$1.3

\footnotetext{
${ }^{6}$ This figure is likely an overestimate. First, it is a post-BID figure. Second, the revenue figures come from the California State Department of Equalization, which assigns each firm to a census block group (small neighborhood). This means that the BID/non-BID distinction can be no finer than the block group. However, BID borders frequently do not follow census block group borders, and thus BID and non-BID firms are given the BID designation. Thus this figure attributes non-BID revenues to BIDs.

${ }^{7}$ This and all data on BIDs comes from city council files, and is described at greater length in the data section.

${ }^{8}$ The city spends about 2 billion dollars on the police, and roughly half of that goes to patrols.
} 
million per square kilometer in the same area. ${ }^{9}$ Thus, though BID expenditures may be small in total, they are locally substantial, sometimes doubling the city's own expenditures. Security expenditures, particularly in the high spending BIDs, are used to either hire private security guards or employ entire crews of colorfully-shirted "neighborhood ambassadors" who patrol the streets, help tourists, deter panhandlers, and communicate via walkie-talkie with the LAPD.

\section{Theoretical Framework}

BIDs are clearly providers of local public goods. Neighborhood security, marketing and cleaning are all prohibitively expensive to provide individually and individual property owners cannot be excluded from their benefits. Why is a BID required to provide these goods? And why do some neighborhoods adopt BIDs while others do not?

In The Logic of Collective Action, Olson (1971) argues that although small groups are able to provide public goods for themselves, large groups uniformly find it difficult to do so. Olson attributes this market failure to the exacerbation of the free rider problem in large groups, as the costs of coordination increase. In the terms of this study, neighborhoods differ in their ability to provide local public goods as a function of the number of neighborhood actors.

Olson suggests two possible mechanisms which allow for the provision of public goods in a large group setting: the exclusion of non-members from the benefits of the public good (which implies that the good cannot be a true public good), or the coercion of all group members into contribution. The first mechanism is inappropriate for neighborhood provision, as excludability is impossible, but the second condition is the essence of the BID law. ${ }^{10}$ After the passage of the 1994

\footnotetext{
${ }^{9}$ BIDs also spend significantly in other ways: the Chinatown BID, at 0.3 kilometers square, in addition to spending on security patrols, spends $\$ 280,000$ annually on cleaning and maintenance. In comparison, the city of Los Angeles spends $\$ 55,000$ per square kilometer (City of Los Angeles, 2003).

${ }^{10}$ In the BID context, an alternative to solving the collective action problem via cooperation is to structurally eliminate the need for cooperation. In the 1960s, cities across the country used the power of eminent domain to seize properties.
} 
BID law, all neighborhoods - those with many and those with few actors - were now able to provide themselves with local public goods, resolving the market failure. ${ }^{11}$

However, even after the passage of the 1994 law, not all neighborhoods adopted BIDs. In deciding whether or not to adopt a BID, a property owner who maximizes the value of his land tallies the costs and benefits of BID formation. If the median property owner in a neighborhood expects the BID to increase the value of his property, the neighborhood will adopt a BID. Since all neighborhoods do not adopt BIDs, there is clearly heterogeneity in the cost and benefit components of forming a BID. This heterogeneity across neighborhoods can be viewed as a desire to Tiebout sort, in a case where the costs of moving for the property owner are high.

This heterogeneity in demand across neighborhoods could be in the quantity and extent of local problems, such as high levels of crime or transients, lack of attention from city officials, or a poor quality of local infrastructure. Though mild versions of such problems, such as a lone visiting homeless person or a temporary blemish on a neighborhood's reputation, may be treatable with individual action, severe versions are not. Heterogeneity in demand may also arise from the fact that severe problems are more detrimental to some neighborhoods than others. For example, street crime is much less important to customers in a neighborhood with gated parking compared to a walking neighborhood of small retail shops. ${ }^{12}$ Finally, heterogeneity in demand may come from the extent to which the amelioration of problems will increase neighborhood property values. Any return to investment depends on whether the improved neighborhood can draw more or wealthier customers, thereby increasing rents and property values. Therefore, this return depends on the wealth of nearby consumers and the neighborhood's transport accessibility.

Cities re-grouped small parcels into large ones and sold them to developers. Amid dual charges of racism and developer cronyism, this brand of urban renewal has largely fallen into disfavor.

${ }^{11}$ In such a majoritarian voting scheme, where the votes are weighted by the benefit each property owner receives, there is a possibility that large property owners could coerce small ones into paying. Empirically, however, the lowest margin of BID passage I found was over two-thirds, so this does not seem to be a concern.

${ }^{12}$ Additionally, some problems are more responsive to investment than others; the responsiveness may further depend on neighborhood characteristics. 
Many of these demand elements are long-standing neighborhood characteristics.

Neighborhood crime levels are persistent, as are the local reputations associated with those levels.

The overall mix of commercial tenants, which determines how the severity of the problem impacts rents, is slow-changing. On the return to investment side, the wealth of nearby shoppers and consumers is relatively steady over time. Also, the neighborhood's physical infrastructure - a feature that changes substantially only with radical redevelopment - determines a neighborhood's collective needs (Brooks, 2006).

In sum, BID adoption should be related to the net impact of long-standing neighborhood characteristics. Any compensatory benefits from BID adoption should be reflected in the value of the median property owner's property, and in important predictors of property value, such as crime (see Thaler's seminal paper (1978)). Indeed, because most BIDs specifically target crime, the theory suggests that crime should drop in BIDs.

Theory also tells us that there should be little local investment before the passage of the 1994 law $^{13}$, and that never-adopting neighborhoods should not increase investment from their initial low level. In addition, there should be no BID provision if BIDs solely crowd out municipal services. Property owners should be unwilling to increase their tax burden without compensatory improvements in service. ${ }^{14}$

\section{Data: Measuring Crime and Neighborhoods}

To measure BIDs' impacts on crime, I use geographically small scale data, both before and after the advent of BIDs, from the LAPD. I combine these data with information on neighborhood

\footnotetext{
${ }^{13}$ This is true with the exception of malls, which I will discuss later.

${ }^{14}$ If BIDs did crowd out municipal services, some early BID formation could be explained by gaming between the city and the BID, but the renewal of older BIDs and the continued formation of new BIDs is impossible to explain. What seems more likely, from the anecdotal evidence and interviews, is that BID neighborhoods are able to more effectively leverage the same amount of police services. For example, BID security guards could do the work of apprehending criminals, and have the police perform the formal arrest.
} 
characteristics from the County Assessor, and with records I have collected on the individual BIDs. These data sources are summarized in Appendix Table 1.

In order to develop a dataset of the adoption date, borders, and expenditures for all BIDs in the city of Los Angeles since their inception, I examined Los Angeles City Council files and spoke with city officials and BID administrators. As a result, I have compiled a unique dataset on the diffusion of BIDs in Los Angeles.

To measure neighborhood characteristics, I use data from the Los Angeles County Assessor purchased from the vendor Dataquick. The Los Angeles County Assessor is the official collector of property taxes and adjudicator of property boundaries, and collects information on each of the 2.2 million properties in the county. This information includes a commercial or residential designation for each parcel, and the year any structure on that parcel was built.

The crime data come from the LAPD, which graciously provided totals for 21 types of crimes and 27 varieties of arrests from 1990 to 2002 by their smallest unit of geography, the reporting district. Each reporting district is either a census tract or a subdivision thereof. The size of the average reporting district, reported in Table 1, is 1.2 square kilometers, but the median is quite a bit smaller, at 0.8 square kilometers. In Figure 1, BIDs are overlaid on a background of polygons, and those polygons are reporting districts. Unfortunately for this researcher, the city of Los Angeles changed the boundaries of these reporting districts over time. By examining maps of these reporting districts over 13 years, I assembled a geographically consistent time series of 1009 reporting districts.

Using GIS software, I matched BID borders with LAPD reporting districts. If a BID is present in a reporting district, I call that reporting district a treated reporting district. ${ }^{15}$ On average, BIDs intersect with approximately 4 reporting districts. Out of the 1009 total reporting districts,

\footnotetext{
${ }^{15}$ Except for a very few cases where the presence of the BID in the reporting district accounts for less that 3 percent of the BID's area.
} 
124 have a BID presence. To attribute BID expenditures to each affected reporting district, I use that reporting district's share of the BID's area. These expenditures by reporting district are displayed in the bottom panels of Table 1 . On average, BIDs spend annually about $\$ 150,000$ total, $\$ 50,000$ of which goes to security, in each reporting district in which they are present.

As did the rest of the country, and major urban areas in particular, Los Angeles experienced a large, across-the-board drop in crime in the mid-to-late 1990s. The decline has flattened out in the present decade. Over the entire sample period, the average reporting district in Los Angeles has 142 serious crimes and 192 less serious crimes. This breakdown follows the FBI classification of crimes, which I will use throughout. Serious crimes include the violent crimes of murder and nonnegligent manslaughter, forcible rape, robbery, and aggravated assault, as well as the nonviolent crimes of burglary, larceny-theft, and motor vehicle theft. ${ }^{16}$

Before the passage of the 1994 BID law, BID reporting districts had, on average, higher crime of all types than the rest of the city, as shown in Table 2. Before 1995, reporting districts with BIDs average 279 serious crimes annually, while all non-BIDs report 175 such crimes. This difference holds true for less serious crime, overall crime, and the three predominant serious crimes of robbery, burglar and auto burglary and theft. ${ }^{17}$ In addition, reporting districts with future BIDs also have a somewhat larger decline in crime than never-BID reporting districts in the pre-BID era.

This differential trend, however, is explained by BIDs' uneven location across the city. To compare BIDs to their wider neighborhoods, I use the LAPD's division of the city into 18 areas, pictured in Appendix Figure 1. These areas are boundaries used for administration, budgeting and patrol deployment by the LAPD. Figure 2 shows BID and non-BID overall crime trends for each LAPD area in the pre-BID years. Crime in BIDs is shown with a solid line, and non-BIDs with a dashed line; areas with only a dashed line have no BIDs. In the vast majority of these cases, BID

\footnotetext{
${ }^{16}$ The LAPD, and other police departments nationally, follow a uniform system of reporting crime. Crimes are divided into Part 1 (serious crimes) and Part 2 (less serious crimes). Part 1 crimes are sometimes referred to as the "index crimes."

${ }^{17}$ This result is similar even when the sample is restricted to substantially commercial neighborhoods.
} 
trends in total crime track non-BID trends very closely, while having somewhat higher levels. ${ }^{18}$ Many of these series show a bump in 1992, attributable to that year's riots. I control for this in the regression with the year fixed effect for 1992, and I control for any fixed-neighborhood level propensity to have riots with the reporting district fixed effect. Though not pictured, the same arealevel pattern holds true for serious and less serious crime separately.

To exclude the possibility that BID neighborhoods experience larger than average increases in crime rates during the crack epidemic of the 1980s, I extend the series back to 1983 for serious crime. Even with the addition of these seven extra years, crime in BID neighborhoods continues to track the pattern of crime in non-BID neighborhood, while at a slightly higher level. In addition, Fryer et al's (2005) Los Angeles-specific crack index for the period is not more correlated with BID than non-BID crime at the area level. Thus, there is no evidence that estimates of the BID effect are attributable to reversion of the mean by neighborhoods affected by the crack epidemic.

\section{Estimation Strategies}

\section{A. $\quad$ Fixed Effects}

A standard OLS estimation of the impact of BIDs on crime is likely biased by the adoption of BIDs in neighborhoods that have the most to gain. ${ }^{19}$ Motivated by the long-standing nature of the problems that induce BID formation, I use a fixed effects approach, comparing crime before and after BID adoption, and controlling for time-invariant characteristics at the neighborhood level. I also control for annual city-wide shocks and area-level trends, which capture overall crime trends in the 18 LAPD areas.

\footnotetext{
${ }^{18}$ Testing this difference, I cannot reject the hypothesis that in all LAPD areas with BIDs, the BID and non-BID trends are jointly equal. This holds true for serious and less serious crime separately.

${ }^{19}$ Theoretically, it is unclear whether the estimates will be up- or downward biased. I offer more discussion on this point later.
} 
Because the neighborhood characteristics - such as high crime - that determine BID adoption are longstanding, the neighborhood $(i)$ fixed effect, based on the reporting district (the vector $\mathrm{rd}_{i}$ ), controls for biases present in the standard OLS framework. Specifically, these fixed effects include distance to the freeway, zoning patterns, and proximity to wealthy customers. Additionally, because commercial property changes hands very infrequently (Brown, 2003), the owners should be considered approximately fixed; constant levels of neighborhood coordination, or personality conflicts are also in this fixed effect.

Also, BIDs are adopted at different times $\left(\mathrm{BID}_{i}{ }^{*}\right.$ after $\left.{ }_{i, t}\right)$, and this timing provides identification of the BIDs' effect. Some of the variation in this timing - the fact that there are no BIDs prior to 1995 - is due to the absence of an enabling law. If the remainder of the variation in adoption timing is determined by neighborhood-specific, unchanging characteristics such as the level of neighborhood organization, then it is controlled for by the fixed effect. In sum, if one believes that BID formation is caused only by time-invariant factors, then this method effectively eliminates the selection problem. ${ }^{20}$

With these elements, the basic model is crime $_{i, a, t}=\beta_{0}+\beta_{1} \mathrm{BID}_{i} *$ after $_{i, t}+\beta_{2, t}$ year $_{t}+\beta_{3, i} \mathrm{rd}_{i}+\beta_{4, a}$ area trend ${ }_{a, t}+\varepsilon_{i, a, t}$

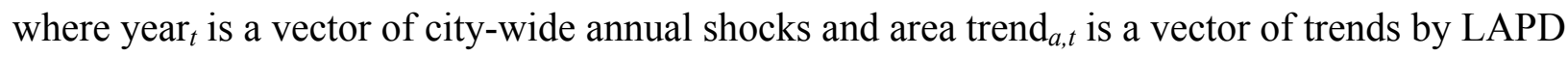
area $(a)$. If BIDs are associated with crime decline, then $\beta_{1}$ will be negative. ${ }^{21}$

\section{B. Matching}

Time-varying causes of BID formation - such as the purchase of neighborhood property by community-minded owners - could lead to a correlation between the BID variable on the right-

\footnotetext{
${ }^{20}$ This assumption will be relaxed in future estimations.

${ }^{21}$ Ideally, crime would be expressed as crimes per customer. Because neighborhood-level time-varying measures of customers are not available, I use level, which, in combination with the reporting district fixed effects, approximates rates relative to residents.
} 
hand side of the estimation and the error. If BIDs are adopted in neighborhoods that are already improving along some dimension, then OLS will overstate declines in crime. If BIDs are adopted in neighborhoods where crime is increasing and no help seems imminent ("desperate" is how one interviewee characterized it (Schatz, 2004)), then OLS will understate the difference in crime. The following estimations address these selection concerns by restricting the control group, explicitly comparing BIDs to other, similar neighborhoods.

To address possible time-varying causes of BID formation, I first match BIDs with almostBID-forming neighborhoods, to control for the non-observable propensity to adopt a BID. Next, I use propensity score matching to test whether BIDs show crime declines relative to other high crime neighborhoods. Finally, I match BIDs with their neighbors to reveal whether crime in BIDs changes relative to nearby areas similarly affected by very local conditions.

\section{B.1. Almost BIDs}

The best empirically feasible control group for BIDs are neighborhoods that very nearly formed BIDs. Such a control group improves upon the fixed effects approach in the event that important time-varying non-observed events propel the BID formation process. For example, BID consideration could be caused by a city council member's change of heart, by change in the income of nearby shoppers, or by a change in city crime policy that affected neighborhoods unevenly.

The two most obvious sources of Almost BIDs are neighborhoods that adopted BIDs after the end of my sample in 2002, and neighborhoods that just voted against BID adoption. As for the first source, in 2003 and 2004, six additional neighborhoods formed BIDs. Neighborhoods that just voted against BID adoption are more scarce. As of 2005, only one neighborhood has voted against a BID. However, this high passage rate is not due to widespread BID adoption, nor to lack of BID consideration. Instead, because property owners acquire a lot of information about their neighbors' 
preferences during the formation process, and because organizing is very costly in terms of time, the BID almost never comes to a vote if it looks unlikely to form.

However, neighborhoods that seriously consider a BID are locatable in the public record. Because the legal requirements to establish a BID are formidable, neighborhoods considering a BID always hire a consultant to guide them through the process. The city of Los Angeles has generally given money for these consultants if the neighborhood can demonstrate seriousness in its BID consideration. Legally, seriousness is conveyed by petitions of support from 15 percent of the potential members, weighted by the value of the assessment. However, it seems that in practice neighborhoods generally have quite a bit more support. In the four files that preserved the tabulation of petitions, three reported support of over 50 percent, and 1 of over 30 percent. I found 21 neighborhoods that either appealed for and received municipal support to hire a consultant, or appeared in other city documents, such as internal memos. The files frequently did not contain the borders of the proposed districts, so I called city council offices and BID proponents to ascertain the borders (see interview citations).

Combining the late adopting BIDs, the 1 non-adopter, and those neighborhoods seriously considering BIDs, I find 26 Almost BIDs. ${ }^{22}$ By construction, then, all neighborhoods in this sample have considered adopting BID services. Along the measurable dimensions, Almost BIDs are the closest to BIDs of any of the matched samples. The first panel of Table 2 shows that across crime types, Almost BIDs are more like BIDs in the distribution and level of crime than all non-BIDs and more like BIDs than BIDs' neighbors. In terms of the propensity score for BID adoption (which I describe in the next section) Almost BIDs fall between all non-BIDs and the BIDs themselves.

\footnotetext{
${ }^{22}$ As I had more confidence in some of the border delineations than others, I estimated the regressions with and without the Almost BIDs with less reliable borders. The results are not substantially different.
} 
However, this section's method is preferable to the propensity score, in that it captures difficult-toquantify aspects of BID-forming attributes such as local personalities and organizational talents. ${ }^{23}$

Assume for a moment that BIDs and Almost-BIDs are identical save for the adoption decision. If BIDs are adopted by improving neighborhoods, and a negative coefficient of $\beta_{1}$ in the previous specification is due entirely to this effect, then the adoption of a BID should have no effect on crime relative to the Almost-BIDs. If the converse is true, and BIDs are adopted in neighborhoods where crime is increasing, then the fixed effect specification may understate the decline in crime, and these results may be larger than the fixed effect ones. Finally, if neighborhoods choose not to adopt a BID because conditions are improving on their own - in other words, because the institution is useless to the non-adopters - then relative to the Almost-BIDs, reporting districts with BIDs should have no discernable pattern in crime behavior. Thus, the comparison of Almost BIDs to BIDs provides a powerful test of the importance of BIDs. In order to implement this test, I re-estimate Equation (1) using only BIDs and Almost BIDs.

\section{B.2. Propensity Score Matching}

The previous estimates non-parametrically match neighborhoods with similar propensities to form a BID. Propensity score matching is a quantitative alternative, matching treated (BID adopting) reporting districts with untreated reporting districts with similar pre-BID characteristics.

With this method, I address how crime changes in BIDs compared to other high-crime neighborhoods and neighborhoods with a similar demand for BIDs.

If the marginal cost of reducing crime falls as the level of crime increases - if it is cheaper to reduce crime when there is a lot of it - crime declines in BIDs could be overstated in comparison to lower crime areas. ${ }^{24}$ This strategy explicitly tests this argument. Specifically, the propensity

\footnotetext{
${ }^{23}$ Additionally, the average Almost BID covers 0.66 square $\mathrm{km}$, about the same as the 0.69 square $\mathrm{km}$ covered by the average BID, and Almost BIDs tend to be in slightly older neighborhoods than BIDs.

${ }^{24}$ One might also want to compare BIDs with similarly commercial neighborhoods. Unfortunately, census tracts are designed to measure residential neighborhoods, and are divided so as to equalize population. Therefore, there are very
} 
score estimating BID adoption includes pre-BID annual levels of serious and less serious crime, comparing BIDs to reporting districts with similar pre-BID levels of crime, non-linear trends in crime, and mix of crimes.

Theoretically, matching should also pair BIDs with reporting districts where owners find a similar potential for an increase in property values. The goal in such a matching would be to find covariates $X_{i}$ such that $\operatorname{Pr}\left(\mathrm{BID}_{i}=1 \mid e\left(X_{i}\right)\right)=\mathrm{P}\left(\mathrm{BID}_{i}=0 \mid e\left(X_{i}\right)\right)$, where $X_{i}$ are the pre-treatment covariates, and $e\left(X_{i}\right)$ is the propensity score. However, factors that predict land price appreciation are as difficult to find as factors that allow investors to beat the stock market - in other words, potential is very difficult to quantify. I use basic population characteristics of the neighborhoodracial and ethnic composition, median income, education, median rents, median home price and home ownership share. ${ }^{25}$ In addition, I identify an important element of neighborhood demand for BIDs and add this to the propensity score.

There is reason to believe that the types of services that BIDs provide are more highly demanded in neighborhoods with older buildings. ${ }^{26}$ For example, by building a wall along the exterior of a mall, or by placing a mall on the inside of a ring of parking lots, the mall provides itself with an effective shield from the problems of homelessness and the quality of pedestrian

few entirely commercial tracts - the vast bulk of reporting districts have commercial properties constituting only a small percentage of overall square footage. However, the neighborhood level fixed effects capture the commercial share of neighborhood property, which is relatively fixed due to zoning regulation.

${ }^{25}$ These variables are listed formally in

Appendix Table 1. As a practical matter, their inclusion affects the results only minimally.

${ }^{26}$ Urban planners have long considered physical neighborhood structure - whether doors face the street or the parking lot, whether buildings are built with enough ground floor retail to encourage pedestrian traffic, whether businesses open directly to the street or onto interior lobbies - to be important in the type and quality of public goods that neighborhoods provide (Jacobs, 1961; Duany and Plater-Zyberk, 1991). 
life. $^{27}$ In contrast, a neighborhood of older businesses with ground floor retail and street or shared parking has a communal interest in lowered crime, cleaner streets and better parking. ${ }^{28}$

The empirical challenge is to identify the year at which the majority of the physical infrastructure was developed, which is a way to quantitatively discriminate between strip malls and street-level retail. Development in Los Angeles has generally followed the pattern of a promoter buying a large tract of land and building (or adding) many homes and businesses at once. In such a development, though an early building might remain standing, the layout would be unrecognizably altered. This suggests that using the earliest year built in each neighborhood could be extremely misleading. However, any small percentile of a neighborhood's year built distribution should give a good approximation of the era of widespread development.

Using the Assessor's property-level information as of 1999, which was the earliest year I was able to obtain, I calculated a distribution of commercial structure year built for each reporting district in the city of Los Angeles. I approximate the era of widespread development with the fifth percentile of commercial structure year built in that reporting district $\left(\mathrm{era}_{i}\right){ }^{29} \mathrm{BID}$ adoption is not tied to this percentile of the distribution; it is correlated, slightly less strongly, with the tenth percentile, and again slightly less strongly with the first quartile. ${ }^{30}$

I therefore estimate the propensity to form a BID as a logistic function of the pre-BID crime and the fifth percentile of the neighborhood's commercial year built distribution:

\footnotetext{
${ }^{27}$ Malls' resolution of externality and incentive issues are well discussed in Gould et al (2002). Most BID structures have an analogy in the mall businesses. For example, BIDs' assessment-weighted voting, which gives major owners a larger voice in BID affairs, parallels the lower rent that anchor tenants pay in malls.

${ }^{28}$ This argument is a specific case of the non-market interactions that Glaeser argues are key to future urban research (2000).

${ }^{29}$ The data are actually geocoded to the census block group, but block groups are usually nested within reporting districts. Reporting districts have an average of 700 commercial parcels; the median is 636. If anything, the data are predisposed not to find an effect of this type, as the Assessor's information on older buildings tends to be less complete than the information about newer ones. If other information is missing for these older properties, it seems likely that they are also more likely to be missing their year built. In other words, the fifth percentile of year built is likely overestimated, and more greatly overestimated for older neighborhoods.

${ }^{30}$ The mean year built for buildings in a reporting district may also be misleading. Two reporting districts, one built entirely in the 1960s, and one built in the 1930s and greatly replaced in the 1990s, could have the same mean age, but vastly different physical layout.
} 


$$
\operatorname{Pr}\left(\mathrm{BID}_{i}=1\right)=\begin{array}{ll}
f & (\text { constant, serious crime } \\
i, 1990 & , \ldots, \text { serious crime } \\
i, 1994, \\
\text { less serious crime } \\
i, 1990, \ldots, \text { less serious crime } \\
\left.i, 1994, \text { era }_{i}, \text { census variables }_{i}\right)
\end{array}
$$

This propensity score compares BIDs more closely than the original fixed effects approach with other neighborhoods likely to adopt BIDs, in terms of crime and physical layout. ${ }^{31}$

In order to present matching results in a format similar to the other results in this paper, I use the combination propensity score-regression method as discussed in Imbens (2004). Using the propensity score $e\left(X_{i}\right)$ predicted from Equation $\backslash$ ref $\{$ match2\}, the regression weights are

$$
\lambda_{i}=\sqrt{\frac{\mathrm{BID}_{i}}{e\left(X_{i}\right)}+\frac{\left(1-\mathrm{BID}_{i}\right)}{\left(1-e\left(X_{i}\right)\right)}}
$$

Using this inverse weighting, I re-estimate Equation (1). As before, theory argues that $\beta_{1}$ should be negative - that BIDs are associated with crime decline. ${ }^{32}$

\section{B.3. Geographic Matching}

In addition to comparing BIDs to neighborhoods with similar crime behavior pre-BID, I also compare changes in crime in BIDs with their neighbors' changes in crime. This comparison is motivated by the belief that neighboring areas may share time-varying causes of BID formation not accounted for by the fixed effects approach. Time varying causes of BID adoption shared by a BID and its neighbors could include changing preferences of the city council member, changes in the quality of the local police administration, sharp changes in the income of nearby shoppers or the level of commercial rents, or changing responsiveness of neighbors to crime. If these effects are indeed constant between the BID and its neighbors, comparing BIDs explicitly to their neighbors nets them out.

\footnotetext{
${ }^{31}$ Results are robust to including the fraction of commercial square feet as a function of total building square feet in a reporting district. However, because reporting districts are constructed from tracts, which are designed to have relatively equal residential population, commercial share varies little across neighborhoods and is thus not a particularly revelatory measure of BID adoption.

32 The inverse weights affect both treated and untreated variables, so I do not present mean crime for the weighted control observations, as it is not comparable with the unweighted crime in BIDs.
} 
Results from this geographic matching are also of interest because they are probably how property owners judge the success of their BID investment. Certainly when BIDs ask consultants to evaluate their work, these consultants compare the BID with its directly surrounding area.

To construct the geographically matched sample, I identified reporting districts adjacent to any BID reporting districts, and called those the neighbors. ${ }^{33}$ The 124 BID reporting districts have 291 direct neighbors. ${ }^{34}$ Like the Almost BIDs, neighbors are more like BIDs than the rest of the city as a whole, as shown in Table 2. Pre-BID crime in these neighbors averages roughly 400 crimes per year, between the figure for BIDs and all non-BIDs. These neighbors also have an elevated propensity to form a BID, roughly 50 percent greater than all non-BIDs.

An additional advantage of geographic matching is that there is a clear "after" for untreated observations, which allows for a true difference-in-difference estimation. Specifically, I add a dummy, after $i, t$, equal to 1 after the treatment for both the treated and the matched untreated. Using this sample, I then estimate ${ }^{35}$ crime $_{i, a, t}=\beta_{0}+\beta_{1} \mathrm{BID} * \mathrm{after}_{i, t}+\beta_{2}$ after $_{i, t}+\beta_{3, t} \mathrm{year}_{t}+\beta_{4, i} \mathrm{rd}_{i}+\beta_{5, a}$ area trend $_{a, t}+\varepsilon_{i, a, t}$

Again, if BIDs are associated with crime declines, I expect $\beta_{1}$ to be negative. ${ }^{36}$

\footnotetext{
${ }^{33}$ Some BID-adjacent reporting districts are themselves BIDs, and I excluded those BIDs from this sample.

${ }^{34}$ These include duplicate reporting districts, as I allow a reporting district to be a first neighbor to multiple BIDs.

35 Instead of the reporting district level fixed effects used in Equation (1), one might also use a fixed effect for the matched group (mgroup), as in crime $_{i, g, a, t}=\beta_{0}+\beta_{1} \mathrm{BID}_{i} *$ after $_{i, t}+\beta_{2}$ after $_{i, t}+\beta_{3, t}$ year $_{t}+\beta_{4, g} \operatorname{mgroup}_{g}+\beta_{5, a}$ area trend ${ }_{a, t}+\varepsilon_{i, a, t}$ However, because the reporting district is nested within the matched group, the reporting district fixed effects are a special case of the matched group fixed effects, and are theoretically preferred.

${ }^{36}$ An alternative to matching that confronts the non-random assignment of BIDs is the use of an instrumental variable. The discussion above suggests a natural instrument - the neighborhood's era of development. When interacted with the passage of the 1994 BID law, this gives a time-varying (as to be separately identified from the reporting district fixed effects) correlate for BID adoption. To be a valid instrument, this measure must be uncorrelated with the outcome variable. It is implausible to argue that a neighborhood's era of development is uncorrelated with its level of crime, and I do not do so here. However, it is mechanically true that net of reporting district fixed effects and city-wide year effects, crime is uncorrelated with the era of development, as the era of development is itself fixed for each reporting district. This instrument is significant in the first stage, and has a large F statistic. The results from the second stage are in the same direction as the other results in this paper, but they are quite a bit larger, and well into the realm of implausibility. Examination of the estimated coefficients on the reporting district fixed effects suggests that the instrument introduces quite a bit of noise into the estimation, and sounds a note of caution for sole reliance even on strong instruments.
} 


\section{Results}

\section{A. Average Effect of BIDs}

\section{A.1. Fixed Effects}

Comparing the pre- and post-BID eras in Table 2 shows BIDs posting larger declines than any comparison group. The regression framework allows for a more careful analysis of this basic result. Results for the fixed effects specification from Equation (1) are presented in the first row of Table $3 .^{37}$ These results indicate that adopting a BID is significantly associated with 51 fewer crimes per year, or with a drop of 9 percent from the pre-BID level. Though less serious crimes are committed more frequently than serious ones, serious crimes make up the bulk of the decline. This pattern of the decline in crime being dominated by the serious crime figures will repeat itself throughout most of the estimation results. The three individual crimes in this table collectively make up almost the entire decline in serious crime, with auto burglary and theft being the most dominant, posting a 19 percent decline. ${ }^{38}$

These are large declines in serious crime - about three-quarters of the roughly 40 percent decline in violent crime experienced by the nation as a whole over the course of the 1990s (Levitt, 2003), and these are on top of the overall decline in crime in Los Angeles over the course of the decade. Is this a plausible size? A randomized trial in Minneapolis that increased police patrols to crime "hot spots" decreased total crime calls between 6 and 13 percent (Sherman and Weisburd, 1995). Another experiment in Jersey City, which addressed additional police support to 12 hot spots found 30 to 60 percent reductions in calls to the police (Braga et al, 1999), and an analysis of gang injunctions in Los Angeles found that they reduced crime by 5 to 10 percent (Grogger, 2002).

\footnotetext{
${ }^{37}$ With the exception of the less serious crime result, all estimates are robust to a square root transformation of the dependent variable (I do not use the log transformation to avoid problems with observations equal to zero.).

${ }^{38}$ In this and all tables, standard errors are clustered at the reporting district level to account for serial correlation within a reporting district.
} 
In other words, these coefficients are not out of line with the effects of other targeted strategies in high-crime neighborhoods.

Unlike from the experiments, however, out-of-sample prediction from this framework is complicated. These results do suggest that states without BIDs could benefit from enabling legislation, but they do not necessarily conclude that a BID would reduce crime in non-adopting neighborhoods in cities that already had BIDs. We can get closer to isolating the BID effect by considering the matching results.

\section{B. Matching}

\section{B.1. Almost BIDs}

A strategy that identifies the BID effect should compare BIDs to neighborhoods just like BIDs, save for the adoption decision; empirically, Almost BIDs are the closest practicable solution to this proposition. Even though the sample size plunges, reporting districts with BIDs still show significant crime declines relative to reporting districts with Almost BIDs, as shown in the second row of Table 3. With a drop of 25 crimes, serious crime still accounts for the lion's share of the 42 crime, or 7 percent, decline. Though this decline is slightly smaller than the original estimates, it is still a large decline - almost one-fifth of the size of the national crime decline of the 1990s. Auto burglary and theft again leads among the individual crimes, posting a decline of 18 crimes. Overall, the coefficients are slightly smaller than those in the initial specification, and the standard errors somewhat larger.

Interestingly, this is the only specification in which the decline in less serious crime is an even partner to the decline in serious crime. Where the previous estimates showed (and the estimates in the following sections will also show) the decline in serious crime swamping the decline in less serious crime, here the coefficients are of the same magnitude. This may suggest that 
there is an important component of less serious crime in the decision to adopt a BID not featured in the other selection correction methods.

\section{B.2. Propensity Score Matching}

Results from propensity score matching, though the smallest in magnitude of all methods employed, tell a broadly similar story. This specification controls non-linearly for pre-BID crime trends, levels and type, neighborhood characteristics, and the demand related to the neighborhood's era of development. Relative to other high crime neighborhoods with similar populations and crime trends and with older infrastructure, BIDs are associated with 29 fewer crimes, or a 5 percent decline in overall crime. Like the initial specification, this decline is predominantly serious crime. Consistent with the previous results, auto burglary and theft shows the largest decline among the serious crimes. Thus, even compared to neighborhoods with similarly high levels of crime, BIDs are associated with crime declines, and follow the same pattern as in the initial specification, though the levels are somewhat reduced. ${ }^{39}$

Though this method produces the lowest estimates of BIDs' association with crime decline, the estimates are still both statistically and economically significant.

\section{B.3. Neighbors}

Like the results from propensity score matching, results from a comparison of BIDs with their neighbors also shows, in the fourth row of Table 3, that BIDs are associated with declines in crime. $^{40}$ These estimates include an after $_{i, t}$ term, which makes the coefficients true difference-indifferences, unlike the previous estimates. Comparing BIDs to their neighbors somewhat reduces

\footnotetext{
${ }^{39}$ One way to validate a matching strategy is to check whether the matched treated and control difference-in-difference is significant before the adoption of the policy, as suggested by Heckman and Hotz (1989). I do not present this for reasons of brevity, but the results concur.

${ }^{40}$ This decline comes from both an absolute decline in crime in reporting districts with BIDs, and a greater decline in reporting districts with BIDs relative to their neighbors. Relative to themselves before the BID, reporting districts with BIDs post an insignificant annual decline of 22 crimes after BID adoption. This insignificance is likely due to the greatly diminished sample size.
} 
the size of the coefficient of interest in the less serious crime estimation relative to the original fixed effects specification, and BIDs are now associated with crime declines of roughly 7 percent. ${ }^{41}$ However, the coefficients of interest remain negative and significant. The decline in serious crime is roughly twice that of less serious crime, and auto burglary and theft accounts for almost a third of the total decline in serious crime.

The inclusion here of the after $_{i, t}$ term does not substantially impact the results. Using serious crime as the outcome, the absolute value of the coefficient of interest when the after ${ }_{i, t}$ term is included is 38 , with a standard error of 7.9. When I drop this term from the estimation, the absolute value of the coefficient increases marginally to 39 , with a standard error of 8.1 . When the other crime categories are used as dependent variables, the coefficient of interest is similarly affected. In all, this strongly suggests that the lack of an "after" term in the other strategies is not a serious problem.

These neighbors also allow for a test of whether BID crime decrease can be attributed solely to BIDs redistributing crime across space. First, note from Figure 1 that BIDs very frequently do not cover the entire reporting district to which they are assigned. If BIDs pushed crime directly out of the BID, but not out of the reporting district, then I would find no effect of BIDs. Since I do find an effect, I can conclusively rule out this type of negative spillover.

Next, if BIDs push crime out to adjacent reporting districts, the crime decline in BIDs relative to their neighbors should be much larger than crime decline relative to the city as a whole. Comparing the first and fourth rows of Table 3, this is not the case. Additionally, it is not theoretically implausible that BIDs may reduce crime. Suppose that newer commercial neighborhoods, such as malls, already have a high cost of committing crime. If the BID law facilitates increasing the cost of crime in older neighborhoods, then the cost of committing a crime

\footnotetext{
${ }^{41}$ The analogous comparison of BIDs relative to their neighbors' neighbors produces estimates that are not statistically different.
} 
in a commercial neighborhood in the city of Los Angeles could increase absolutely, which would lead to lowered crime overall. This is not entirely the case, since not all older neighborhoods form BIDs, but it can certainly explain some of the decline.

In sum, all three matching strategies have uniformly shown that BIDs are associated with significant declines in crime. ${ }^{42}$ The most theoretically appealing of these strategies, comparing BIDs with Almost BIDs, estimates a 8 percent drop in overall crime, composed of a 6 percent drop in less serious crime, and a 9 percent drop in serious crime.

\section{Extensions \& Robustness Checks}

Apart from BIDs' overall impact on crime, it is also of interest to consider how much BIDs spend on crime reduction, and whether that crime reduction comes at the expense of other neighborhoods. In addition, this section summarizes robustness checks which are consistent with the theory: that certain types of BIDs are more effective than others, and that certain types of crime should be more affected than others. ${ }^{43}$

By replacing the dummy for BID adoption in the regressions above with a measure of BID expenditure, a decline of 1 reported crime is associated with $\$ 546$ to $\$ 4,764$ of total BID expenditure and $\$ 1,096$ to $\$ 1,569$ of BID security expenditure (this section is explained in greater detail in an appendix not intended for publication). Averaging these two figures, a decline of 1 crime is associated with a relatively narrow range of $\$ 2,000$ to $\$ 3,000$ of BID expenditure. ${ }^{44}$ In some sense these are underestimates of BID effectiveness, as BID security also addresses nonreported offenses, such as the presence of transients. My results suggest that 1 out of 7 averted

\footnotetext{
${ }^{42}$ Though the coefficients are almost all significantly different from zero, they are not statistically different from one another.

${ }^{43}$ More detail on all these estimations is available in an appendix not intended for publication.

${ }^{44}$ Ideally, I would compare this with the LAPD's cost per crime averted. Unfortunately, the closest reliable figures are national averages that I cite in the introduction (Levitt 2004). For a sense of the magnitude of local police expenditure, the LAPD spends approximately $\$ 5,000$ per committed crime.
} 
crimes are violent ones. Compared to the conservative estimate of $\$ 57,000$ of social cost per violent crime, BIDs are cheap.

To evaluate whether crime reduction comes at the cost of enforcement in other neighborhoods, it would be ideal to examine the crime clearance rate by reporting district. Because these data are not available at the reporting district level, the analysis focuses on comparing BIDs' impact on arrests to their impact on crime. If BIDs simply crowd out city services, there is no theoretical reason for their continued adoption. However, there is a possibility that BIDs, through their greater voice in having resolved the neighborhood collective action problem, could act as a magnet for city services; in this case, we would expect BIDs to have a great impact on those arrests that are the most discretionary. Using the four estimation methods above to compare BIDs' impact on arrests, BIDs do not show an increase in more discretionary arrests relative to less discretionary ones. Thus, this is evidence that any BID impact on enforcement is modest at best.

Though the analysis thus far has taken BIDs as a homogeneous group, the city of Los Angeles actually has both property- and merchant-based BIDs. Property based BIDs assess property owners, run for a finite term, usually 3 to 5 years, and require a new vote to re-establish at the end of this term. Merchant-based BIDs assess business owners, and, after an initial vote, require a majority assessment-weighted protest to become inactive. Theory suggests that property owners should be willing to make larger investments in neighborhoods as they are the residual claimant to any successful investment. Though merchants also have an interest in improving their neighborhood, they are priced out if it is improved too much. The theoretical prediction of property BIDs' greater willingness to invest is borne out by their disproportionate share -90 percent - of all BID investment, though property BIDs only account for 20 of the 30 BIDs in Los Angeles. Dividing the BID effect into property BID and merchant BID components, property BIDs are associated with much larger declines in crime across estimation methods than merchant BIDs: in the fixed effects approach, property BIDs are associated with a roughly 12 percent decline in 
crime, while merchant BIDs are associated with an insignificant drop of 3 percent. This pattern holds across all estimation methods, and the minimum crime decline associated with property BIDs is 38 crimes, or 7 percent.

Theory leaves an open door for BIDs' impact on crimes they do not seek to directly address: the resolution of a neighborhood's collective action problem could have beneficial effects even for non-targeted crimes. ${ }^{45}$ To assess this impact, compare BIDs' impact on crime they are likely to affect - robbery, theft, and assault - to crimes that BIDs are unlikely to affect -- forgery (by far the largest contributor to the total), fraud, embezzlement, family crimes (domestic abuse) and nonprostitution sex crimes (i.e., child abuse). Across estimation strategies, BIDs are less likely to be associated with declines in the mix of unlikely crimes than they are with robbery. Of the four estimation strategies, only 2 find an association between BIDs and the unlikely crimes, and then it is small.

\section{Conclusion}

By giving neighborhoods a tool to solve the collective action problem they face in the provision of public safety, the 1994 BID law has allowed Los Angeles neighborhoods to take charge of their own security. Across a range of estimation methods, BIDs are associated with crime declines of 5 to 9 percent. Strikingly, BIDs are more frequently associated with declines in serious than less serious crime. The matching results show that this decline is attributable neither to BIDs exporting crime, nor to a lower marginal cost of reducing crime in high crime neighborhoods.

When BID expenditures are used as an independent variable, roughly \$3,000 of BID spending is associated with a decline of one additional crime. Attributing all this spending to

\footnotetext{
${ }^{45}$ Broken windows advocates, led by Wilson and Kelling (1982), would argue that improvements in quality-of-life crimes would lead to improvements in all types of crimes.
} 
BIDs' reduction in violent crime, this comes to roughly $\$ 21,000$ of BID spending per averted violent crime. Compared to Levitt's (2004) estimate of $\$ 20,000$ to $\$ 86,000$ of police spending per violent crime, BIDs are both more efficient and more targeted. This comparison aside, it is clear from the perspective of a property owner that an additional $\$ 3,000$ of taxes is more preferably spent and controlled locally than watered down across the city. From a social welfare perspective, the BID law is the essential policy that allows neighborhoods to provide locally desirable public goods. The law allows neighborhood property owners to exercise Tiebout-like flexibility, without the expense of voting with their feet.

In the final analysis, however, how BIDs cause crime decline is essential to understanding whether any BID-like policy is healthy for the city at large. The quantitative evidence, together with anecdotal evidence, suggests that the city is constrained to provide a similar level of service in all areas, and that BIDs are modestly able to change the composition of those services. On net, the city must balance this redistribution of services with any crime declines caused by BIDs. In the evidence presented here, the crime declines associated with BID adoption are sizable; the evidence with respect to enforcement was substantially more mixed. Certainly, the BID mechanism of providing public goods outside of the municipal government has been enthusiastically embraced by some neighborhoods. With this modification of the law, small property owners can compete more directly with large property owners and others interested in consumer dollars and municipal attention.

More generally, the resolution, by BIDs, of collective action failure through coercive membership has implications for place-based public goods providers, such as schools or homeowners' associations, as well as professional or trade associations. In addition, the importance of physical infrastructure that I have outlined here for BIDs is relevant to theoretical, empirical and policy-relevant work about the nature of urban areas. 
BIDs' success emphasizes the importance of well-functioning local institutions. Many of the public goods that are essential for economic growth - security, property rights, lack of corruption - have important local aspects. This research shows that well-designed local institutions are essential to providing public goods, and that the public goods those institutions provide are essential inputs to economic growth. 


\section{References}

Alesina, Alberto, Baquir, Reza and Hoxby, Carolyn, 2004. "Political Jurisdictions in Heterogeneous Communities.” Journal of Political Economy 11(2): 348-396.

Angrist, Joshua, Imbens, Guido and Rubin, Donald B., 1996. "Identification of Causal Effects Using Instrumental Variables." Journal of the American Statistical Association 91: 444-455.

Bertrand, Marianne, Duflo, Esther, and Mullainathan, Sendhil, 2004. "How Much Should We Trust Difference-in-Difference Estimates?” Quarterly Journal of Economics 119(1): 249-75.

Braga, Anthony, et al, 1999. "Problem Oriented Policing in Violent Crime Places: A Randomized Controlled Experiment.” Criminology 37(3): 541-580.

Brooks, Leah, 2005. "Who Volunteers to be Taxed? Business Improvement Districts and the Distribution of Extra-Governmental Provision of Public Goods.” Unpublished manuscript.

Brooks, Leah, 2006. "Unveiling Hidden Districts: Assessing the Adoption Patterns of Business Improvement Districts in California.” McGill University Working Paper.

Brown, Brian, 2003. "Exploring Reassessment of Commercial Property Owned by Legal Entities." California Senate Office of Research Report.

Calanog, Victor Franco M., 2004. "Business Improvement Districts: Crime Deterrence or Displacement?” Unpublished manuscript.

Cohen, Mark et al, 2004. "Willingness-to-Pay for Crime Control Programs." Criminology 42(1): 89-109.

City of Los Angeles, 2003. "City of Los Angeles 2002-3 Budget Summary.” Tech. rep., City of Los Angeles.

Cullen, Julie Berry and Levitt, Steven D., 1999. "Crime, Urban Flight, and the Consequences for Cities.” Review of Economics and Statistics LLXI(2): 159-169.

Demsetz, Harold, 1970. "The Private Provision of Public Goods." Journal of Law and Economics 13(2): 293-306.

Di Tella, Rafael, and Schargrodsky, Ernesto, 2004. "Do Police Reduce Crime? Estimates Using the Allocation of Police Forces After a Terrorist Attack." American Economic Review 94(1): 11533.

Duany, Andres and Plater-Zyberk, Elizabeth, 1991. Towns and Town-making Principles. Harvard University Graduate School of Design and Rizzoli.

Dye, Richard F., and Merriman, David F., 2000. "The Effects of Tax Increment Financing on Economic Development." Journal of Urban Economics 47: 306-328.

Epple, Dennis and Romano, Richard, 1996. "Public Provision of Private Goods.” Journal of Political Economy 104:57-84. 
Fryer, Roland G., Jr., 2005. "Measuring the Impact of Crack Cocaine.” NBER Working Paper No. 11318.

Glaeser, Edward, 2000. "The Future of Urban Research: Non-Market Interaction.” Brookings Wharton Papers on Urban Affairs pages 101-38.

Gould, Eric D., Pashigian, Peter B., and Prendergast, Canice, 2002. "Contracts, Externalities, and Incentives in Shopping Malls.” CEPR Discussion Paper No. 3598.

Grogger, Jeffrey, 2002. "The Effects of Civil Gang Injunctions on Reported Violent Crime: Evidence from Los Angeles County." Journal of Law and Economics XLV: 69-90.

Heckman, James and Hotz, V. Joseph, 1989. "Choosing Among Alternative Nonexperimental Methods for Estimating the Impact of Social Programs: The Case of Manpower Training." Journal of the American Statistical Association 84(408): 862-874.

Helsley, Robert W. and Strange, William C., 1998 "Private Government." Journal of Public Economics 69:281-304.

Helsley, Robert W. and Strange, William C., 1999. "Gated Communities and the Economic Geography of Crime.” Journal of Urban Economics 46: 80-105.

Houston, Jr., Lawrence O., 2003. Business Improvement Districts. Urban Land Institute in cooperation with the International Downtown Association, second edn.

Hoyt, Lorlene, 2004. "Collecting Private Funds for Safer Public Spaces: An Empirical Examination of the Business Improvement District Concept." Environment and Planning B: Planning and Design 31: 367-380.

Imbens, Guide W., 2004. "Nonparametric Estimation of Average Treatment Effects Under Exogeneity: A Review." The Review of Economics and Statistics 86(1): 4-29.

Jacobs, Jane, 1961. The Death and Life of Great American Cities. New York: Random house.

Konrad, Kai, 1994. "The Strategic Advantage of Being Poor: Private and Public Provision of Public Goods.” Economica 61: 79-92.

Levitt, Steven D., 2004. "Understanding Why Crime Fell in the 1990s: Four Factors That Explain the Decline and Six That Do Not." Journal of Economic Perspectives 18(1): 163-190.

Levitt, Steven D., 1997. "Using Electoral Cycles in Police Hiring to Estimate the Effect of Police on Crime: Reply." American Economic Review 92(4): 1244-1250.

Los Angeles Police Department, Information Technology Division, 2003. Statistical Digest 2003. Los Angeles Police Department.

Mitchell, Jerry, 2001. 'Business Improvement Districts and the 'New' Revitalization of Downtown." Economic Development Quarterly 15(2): 115-123.

Olson, Mancur, 1971. The Logic of Collective Action: Goods and the Theory of Groups. Harvard University Press. 
Ostrom, Elinor, 1990. Governing the Commons: The Evolution of Institutions of Collective Action. Cambridge University Press.

Peters, Alan H. and Fisher, Peter S., 2002. State Enterprize Zone Programs: Have They Worked? Upjohn Institute for Employment Research.

Sherman, Lawrence W. and Weisburd, David, 1995. "General Deterrent Effects of Police Patrol in Crime 'Hot Spots': A Randomized, Controlled Trial.” Justice Quarterly 12(4): 625-648.

Thaler, Richard, 1978. "A Note on the Value of Crime Control: Evidence from the Property Market." Journal of Urban Economics 5: 137-145.

Tiebout, Charles M., 1956. “A Pure Theory of Local Expenditures.” Journal of Political Economy 64(5): 416-424.

Wilson, James Q., and Kelling, George L., 1982. "Broken Windows: Police and Neighborhood Safety." Atlantic Monthly pages 29-36.

\section{Interviews}

\section{City Employees}

Patrice Lattimore, BID Administrator, City of Los Angeles. Multiple contacts, 2002-2004.; Angus McKenzie, BID Administrator, City of Los Angeles. Multiple contacts, 2002-2004.; Senior Lead Officer Chuck Moore, Hollywood Area BID contact, LAPD. September 2004,; Gary Murakami, Manager, BID Program, City of Los Angeles. Multiple contacts, 2002-2004.; Rick Scott, BID Administrator, City of Los Angeles. Multiple contacts, 2002-2004.

\section{BID Officials}

Richard Bradley, CEO, Downtown DC BID; Past President, International Downtown Association. Washington, DC, Aug. 2003.; Darryl Holter, CEO, Figueroa Corridor BID. Los Angeles, Nov. 2003.; Michael Jenkins, Lawyer; former city of San Diego economic development official; current BID consultant. San Diego, Dec. 2003.; Carol Schatz, President and CEO, Central City Association (Los Angeles), and Los Angeles Downtown Center Business Improvement District. April 2004.; Dora Herrera, Los Feliz BID. Phone and email, March 2005.

\section{Others}

Richard Bogy, President, Toluca Lake Chamber of Commerce; Organizer, defunct Toluca Lake BID. Phone, Aug. 2004.; Roxanne Brown, Business Outreach Chair, Pico Revitalization Project; Organizer, defunct Pico Corridor BID. Phone and email, Aug. 2004.; Frances Ann Carley, North Hollywood Arts Association (organization with ties to defunct North Hollywood BID). Email and phone, Aug. 2004.; Edward Henning, BID Consultant; Consultant, defunct Eagle Rock BID. Email, Aug. 2004.; Frank O'Brien, Harbor-Watts Economic Development Commission; contact for defunct Watts BID. Phone, Aug. 2004.; Susan Levi, Susan Levi and Associates. Email March 2005.; Marco LiMandri, Principal, New City America. Phone and email, March 2005.; Toshonya Olive, Downtown Resources. Phone and Email, March 2005. 
Figure 1 City of Los Angeles Police Reporting Districts and Business Improvement Districts

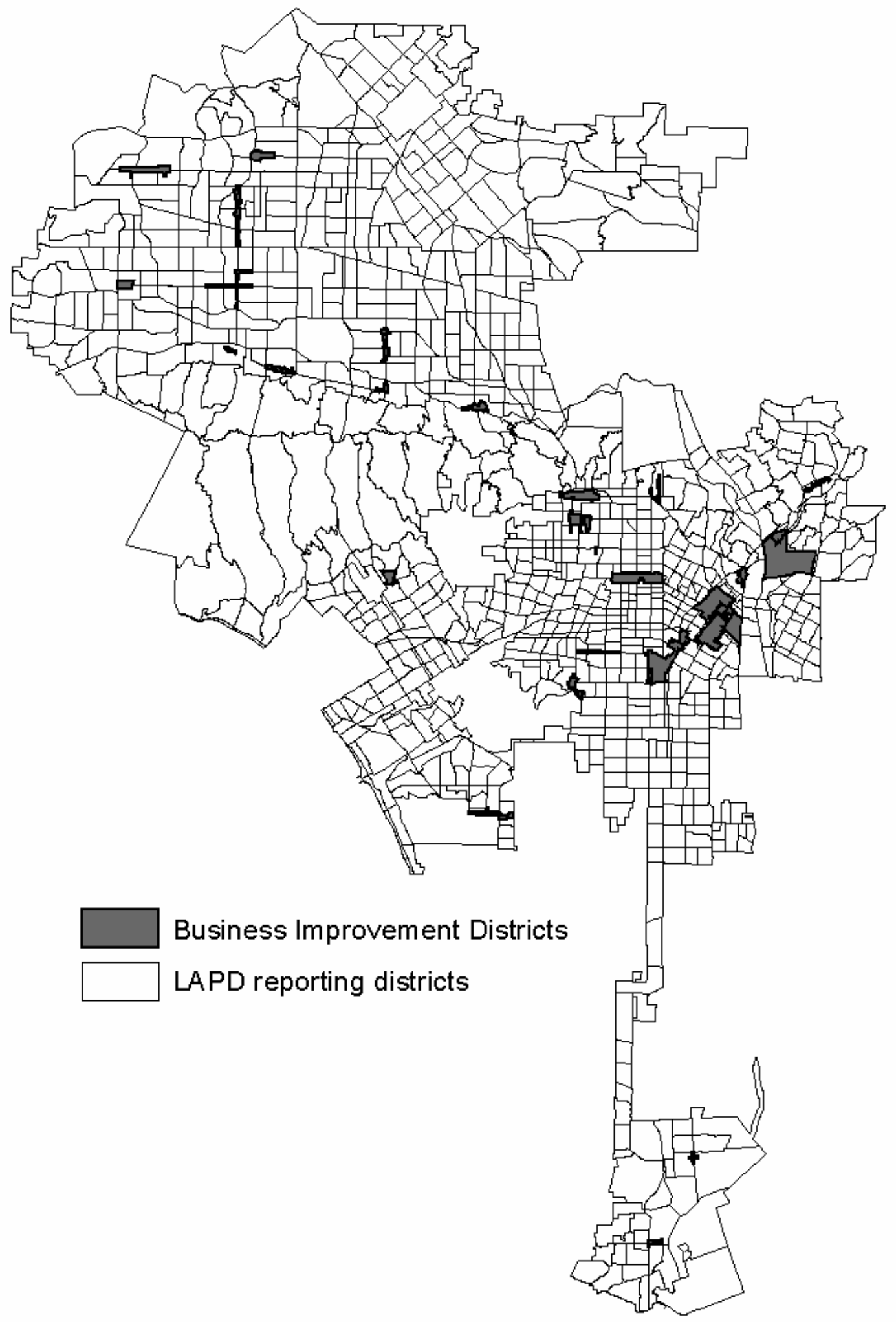

Source: Author's compilation from City of Los Angeles Planning Department geographic data.

Notes: The small polygons in the figure are the neighborhoods (reporting districts) by which the Los Angeles Police Department reports crime. The dark-outlined polygons are Business Improvement Districts. 


\section{Figure 2 LAPD Area-Level Trends}

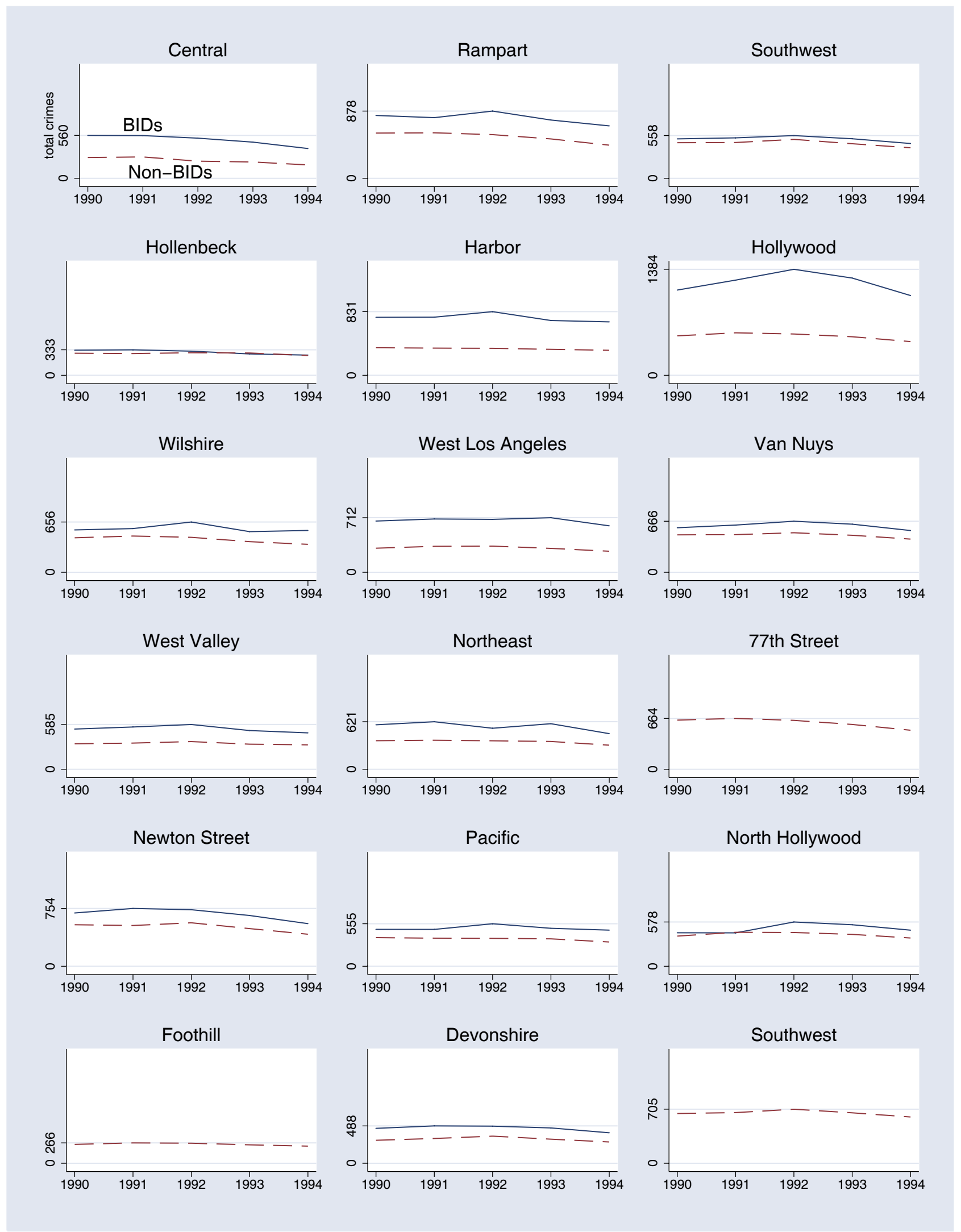

Notes: This chart shows that, by LAPD area, the pre-BID-law trend in crime in reporting districts with BIDs (solid line) is very similar to the pre-BID trend in reporting districts without BIDs (dashed line). Some areas have no BIDs. Source: Author's compilation from Los Angeles Police Department geographic data. 
Table 1 BID Size and Expenditures

\begin{tabular}{lcc}
\hline \hline Size, in square kilometers & & \\
\hline & mean & median \\
BIDs & 0.69 & 0.37 \\
reporting districts (LAPD neighborhoods) & 1.23 & 0.81 \\
& & \\
Expenditures by BIDs & & \\
\hline & & all BIDs with \\
& & positive security \\
& all BIDs & expenditures \\
\cline { 2 - 3 } number & 30 & 19 \\
total budget (\$) & & \\
average & 628,843 & 924,262 \\
median & 282,180 & 501,827 \\
$\quad$ total & $18,865,293$ & $17,560,985$ \\
security budget $(\$)$ & & \\
$\quad$ average & 216,594 & 341,990 \\
median & 23,144 & 210,842 \\
total & $6,497,813$ & $6,497,813$
\end{tabular}

Expenditures by BIDs by Reporting District (RD)

number of reporting districts

\begin{tabular}{cc}
$\begin{array}{c}\text { all RDs with } \\
\text { BIDs }\end{array}$ & $\begin{array}{c}\text { all RDs with } \\
\text { positive security } \\
\text { expenditures }\end{array}$ \\
\hline 124 & 85
\end{tabular}

total budget

mean

152,139

206,600

median

78,747

113,817

security budget

mean

52,402

76,445

median

17,323

37,429

Notes: The reporting district is the LAPD's smallest unit of analysis, and is a census tract or smaller. The average BID intersects with four reporting districts. These figures are for unique reporting districts; three reporting districts have two BIDs present.

Source: Author's tabulations from Los Angeles City Council file, City of Los Angeles maps, and the Los Angeles Almanac. 
Table 2 BIDs and Control Groups

\begin{tabular}{|c|c|c|c|c|c|c|c|c|}
\hline & \multirow[b]{2}{*}{$\begin{array}{l}\text { reporting } \\
\text { district-year } \\
\text { observations }\end{array}$} & \multicolumn{3}{|l|}{ totals } & \multicolumn{4}{|c|}{ serious crimes } \\
\hline & & serious & less serious & overall & robbery & burglary & $\begin{array}{l}\text { auto } \\
\text { burglary } \\
\text { and theft }\end{array}$ & $\begin{array}{l}\text { mean } \\
\text { propensity } \\
\text { score }\end{array}$ \\
\hline \multicolumn{9}{|l|}{ Before 1995} \\
\hline BIDs & 620 & 278.9 & 300.1 & 578.9 & 50.2 & 65.4 & 118.3 & 0.279 \\
\hline all non-BIDs & 4,425 & 174.9 & 216.7 & 391.7 & 33.8 & 48.3 & 59.0 & 0.096 \\
\hline Almost BIDs & 660 & 231.3 & 250.6 & 481.9 & 54.2 & 58.6 & 68.0 & $0.129^{46}$ \\
\hline Neighbors & 1,455 & 179.1 & 219.8 & 398.9 & 32.2 & 46.2 & 70.6 & 0.136 \\
\hline \multicolumn{9}{|l|}{1995 and After } \\
\hline BIDs & 992 & 154.0 & 232.9 & 386.9 & 26.2 & 34.1 & 65.5 & \\
\hline all non-BIDs & 7,080 & 107.5 & 162.2 & 269.7 & 18.0 & 27.3 & 40.7 & \\
\hline Almost BIDs & 1,056 & 136.3 & 193.7 & 330.0 & 27.8 & 31.4 & 45.5 & \\
\hline Neighbors & 2328 & 102.6 & 158.0 & 260.6 & 16.5 & 24.8 & 43.2 & \\
\hline
\end{tabular}

Notes: This table shows that crime is higher in BIDs relative to all non-BIDs; comparison groups have crime levels between BIDs and all-non BIDs. After the passage of the BID law, crime declines in all groups. The mean in this table represents the sample used in the fixed effects regressions. For the Almost BID calculations, I drop reporting districts that have both BIDs and Almost BIDs. For the neighbors calculations, I resample reporting districts if they belong to more than one BID or are neighbors to more than one BID.

Source: Crime data from LAPD; BID information is author's tabulations from city documents.

\footnotetext{
${ }^{46}$ This row contains average crime and the average propensity score for the observations used in the regressions below, which drop reporting districts which are both BIDs and Almost BIDs. Keeping those reporting districts in the average propensity score, this figure rises to 0.145 .
} 
Table 3 Regressing BID Adoption on Crime

\begin{tabular}{|c|c|c|c|c|c|c|c|}
\hline & \multirow[b]{2}{*}{ observations } & \multicolumn{3}{|l|}{ totals } & \multicolumn{3}{|c|}{ serious crimes } \\
\hline & & serious & $\begin{array}{l}\text { less } \\
\text { serious }\end{array}$ & overall & robbery & burglary & $\begin{array}{l}\text { auto } \\
\text { burglary } \\
\text { and theft }\end{array}$ \\
\hline Fixed & 13,117 & & & & & & \\
\hline \multirow[t]{2}{*}{ Effects } & & -40.62 & -10.43 & -51.05 & -5.82 & -8.39 & -23.34 \\
\hline & & $8.01 * *$ & $5.28^{*}$ & $11.10 * *$ & $1.33 * *$ & $1.88 * *$ & $5.14 * *$ \\
\hline Almost & 3,250 & & & & & & \\
\hline \multirow[t]{2}{*}{ BIDs } & & -25.26 & -16.72 & -41.98 & -1.56 & -3.35 & -17.48 \\
\hline & & $10.08^{*}$ & $6.38 * *$ & $14.31 * *$ & 2.04 & 2.44 & $6.05^{* *}$ \\
\hline \multirow[t]{2}{*}{ Matching } & 12,935 & -22.07 & -8.42 & -29.90 & -2.81 & -4.46 & -14.08 \\
\hline & & $5.29 * *$ & 5.00 & $8.67 * *$ & $1.11^{*}$ & $1.39 * *$ & $3.23 * *$ \\
\hline \multirow[t]{2}{*}{ Neighbors } & 5,434 & -38.14 & -5.21 & -43.35 & -6.36 & -8.19 & -20.51 \\
\hline & & $7.92 * *$ & 6.22 & $12.00 * *$ & $1.46^{* *}$ & $2.01 * *$ & $5.10 * *$ \\
\hline
\end{tabular}

* Significant at the $0.01 \%$ level. ** Significant at the $0.05 \%$ level.

Notes: The coefficient of interest, $\beta_{1}$ is that on the $\mathrm{BID}_{i}{ }^{*}$ after ${ }_{i, t}$ term, and this table states that, using the fixed effects approach, BID adoption is associated with 41 fewer crimes. All regressions in this table include reporting district fixed effects, year fixed effects, and LAPD area-level trends. The neighbors regressions additionally include an after ${ }_{i, t}$ term. In this and all future tables, standard errors are clustered at the reporting district level. When calculating BID performance relative to Almost BIDs, I drop 9 reporting districts which contain both a BID and an Almost BID. In the matching regressions, the sample size drops because all reporting districts do not have property information; e.g. the $\mathrm{RD}$ is a park. In the neighbors sample, because I include duplicate reporting districts, there are 3 more BID reporting districts than the previous sample; three reporting districts contain two BIDs. The neighbors sample uses the unique timing of each BID/reporting district combination to determine the timing of BID adoption. All regressions control for reporting district fixed effects (1009), year effects (12), and area-level trends (17).

Source: Crime data from LAPD; BID information is author's tabulations from city documents. Information on properties from the Los Angeles County Assessor's Office, purchased from Dataquick. 


\section{Appendix Figure 1: Los Angeles Police Department Areas}

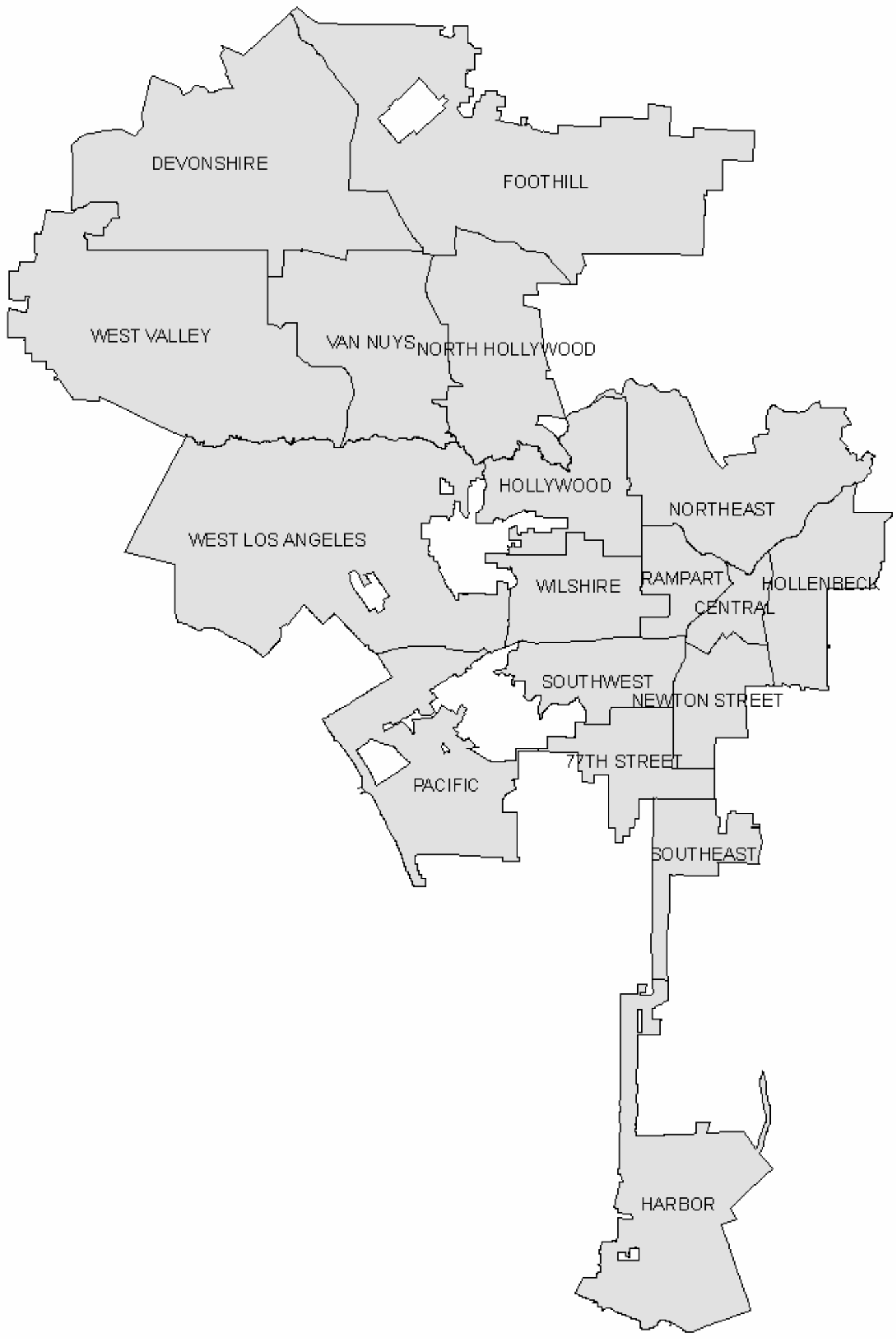

Note: This picture shows the 18 areas used by the LAPD for staffing and budgeting.

Source: Geographic file from the Los Angeles Police Department. 
Appendix Table 1: Data Sources Used

\begin{tabular}{|c|c|c|c|}
\hline Dataset & Source & Unit of Observation & Variables \\
\hline BID Information & $\begin{array}{l}\text { - current \& historical city council files } \\
\text { - interviews: BID members, city } \\
\text { officials, \& those who considered } \\
\text { adopting a BID } \\
\text { - BID and community group websites }\end{array}$ & $\begin{array}{l}\text { - } \text { BID } \\
\text { - Almost BID }\end{array}$ & $\begin{array}{l}\text { - } \text { BID adoption year } \\
\text { - BID location } \\
\text { - BID expenditures, each year } \\
\text { of operation } \\
\text { - Almost BID location }\end{array}$ \\
\hline Crime & Research Department, LAPD & $\begin{array}{l}\text { - } 1009 \text { reporting districts } \\
\text { - } 1990-2002, \text { linked } \\
\text { geographically by the author }\end{array}$ & $\begin{array}{l}\text { - } 21 \text { types of crime } \\
\text { - } 27 \text { types of arrests }\end{array}$ \\
\hline $\begin{array}{l}\text { Property } \\
\text { Information }\end{array}$ & $\begin{array}{l}\text { Los Angeles County Assessor, via } \\
\text { Dataquick Inc. }\end{array}$ & $\begin{array}{l}\text { parcel, geocoded to the } \\
\text { block group level }\end{array}$ & $\begin{array}{l}\text { - year structure was built } \\
\text { - designation of property as } \\
\text { commercial or residential }\end{array}$ \\
\hline $\begin{array}{l}\text { Neighborhood } \\
\text { Characteristics }\end{array}$ & Census Summary Tape File 3A & - census tract & $\begin{array}{l}\text { - percentage Black } \\
\text { - percentage Asian } \\
\text { - percentage Hispanic } \\
\text { - median family income } \\
\text { - percentage with high school } \\
\text { - } \text { education or less } \\
\text { - educentage with any college } \\
\text { - median rent } \\
\text { - median value of owner- } \\
\text { occupied housing } \\
\text { - percentage owner-occupied } \\
\text { dwellings }\end{array}$ \\
\hline
\end{tabular}




\section{Appendix: Additional Material Not Intended for Publication}

\section{Expenditures}

So far the estimates have relied upon a dummy as the marker for BID adoption. If BIDs differ in strength or effectiveness, the resulting coefficient reports the average effect across all BIDs. Replacing this dummy with a measure more closely aligned with BID strength - total BID expenditure or BID security expenditure - allows for a per dollar estimate of the benefits of BID adoption, as shown in Table 4. Specifically, the $\mathrm{BID}_{i}{ }^{*} \operatorname{after}_{i, t}$ term in Equation (1) (or its equivalent) is replaced by BID expenditure $i, t$. Theory suggests that the correct amount of expenditure to use in such a regression would be some amount between the higher total expenditure and the lower security expenditure. Security expenditures clearly go directly toward combating crime, but the total expenditure may also go toward solving free rider problems that would otherwise prove a hindrance to crime reduction, such as disputes among neighbors about the correct disposition of public space.

Each cell in the first two columns of Table 4 comes from a regression of crime on BID total and security expenditure separately, using the control variables described above. The two righthand columns translate these regression coefficients into a dollar per crime averted figure. Here a decline of 1 reported crime is associated with $\$ 546$ to $\$ 4,764$ of total BID expenditure and \$1,096 to $\$ 1,569$ of BID security expenditure. Averaging these two figures, a decline of 1 crime is associated with a relatively narrow range of $\$ 2,000$ to $\$ 3,000$ of BID expenditure. ${ }^{47}$ Among the dollar figures from the coefficient on the security budget, not one tops $\$ 2,000$ per reported crime

\footnotetext{
${ }^{47}$ Re-calculating these estimates by dividing total BID expenditure (or security expenditure) by the total crime averted by BIDs yields very similar results. This suggests that these results are not driven by the endogeneity of the choice of spending.
} 
averted. ${ }^{48}$ In some sense these are underestimates of BID effectiveness, as BID security also addresses non-reported offenses, such as the presence of transients. My results suggest that 1 out of 7 averted crimes are violent ones. Compared to the conservative estimate of $\$ 35,000$ of social cost per violent crime, BIDs are cheap.

From the perspective of the property owner, it is certainly preferable to spend $\$ 3,000$ extra in taxes in front of one's own front door than to lobby for higher city-wide taxes for police. The low price of BID provision also indicates that this local provision is more efficient from a social welfare viewpoint. Local actors choose the level of provision that best suits them, and they provide it at a lower cost.

\section{Enforcement}

The results of this paper strongly suggest that BIDs are able to lower crime. But how do BIDs lower crime? Theory suggests that BIDs do not lower crime by crowding out municipal services. However, it is certainly possible that BIDs could lower crime by doing the reverse - by acting as a magnet for municipal services. In the unlikely event that BIDs crowd out police services, the city as a whole benefits; if BIDs capture city services, they harm overall municipal security and have detrimental redistributive repercussions. Here I assume that the city is constrained, legally and politically, to offer a similar quantity of police service across the entire city. ${ }^{49}$

\footnotetext{
${ }^{48}$ Ideally, I would compare this with the LAPD's cost per crime averted. Unfortunately, the closest reliable figures are national averages that I cite in the introduction (Levitt 2004). For a sense of the magnitude of local police expenditure, the LAPD spends approximately $\$ 5,000$ per committed crime.

${ }^{49}$ This assumption is empirically grounded. Of all the measures of police distribution across the 18 LAPD areas police expenditure per capita, per square mile, per street mile and per crime - expenditure per crime has the smallest coefficient of variation.
} 
One way in which BIDs could decrease crime is by doing tasks the LAPD might not be willing or financially able to do, such as keeping a closer eye on the streets, moving homeless people along, frequently scolding drunks, and aggressively pursuing unlicensed street vendors. All of these activities increase the cost of committing a crime. Certainly some BIDs do exactly these things through their full-time staffs of "neighborhood ambassadors." If BIDs decrease crime in this fashion, it suggests that private services supplement, but do not crowd out, public ones.

It is also very plausible that neighborhood with a BID could be better mobilized to attract more police enforcement, possibly because the neighborhood may now have full-time staff members to call when the police could be helpful. For example, the Hollywood Entertainment BID purchased wireless cameras to monitor Hollywood Boulevard, which will be operated by the LAPD (Ofc. Moore 2004).

To measure police enforcement at the neighborhood level, I investigate changing arrest patterns by the type of arrest. In general, arrests of all kinds decline after BID adoption, along with the number of crimes. However, if BIDs were to attract greater police enforcement, we would expect larger increases in arrests that are more discretionary relative to those that are less discretionary. The most discretionary arrest category in my sample is drunkenness, for which there is no corresponding crime. In comparison, I examine arrests for burglary and vehicle theft. Though these types of arrests may allow for some discretion, it is surely less than is allowed for in arrests for drunkenness. Therefore, if BIDs are able to draw significant police attention, they should have smaller decline in arrests for drunkenness relative to arrests for burglary and vehicle theft.

The right-hand panel of Table 6 presents the results of regression BID adoption on three kinds of arrest outcomes - burglary, vehicle theft, and drunkenness. Over this period, the reported 
crimes of burglary and vehicle theft drop dramatically; drunkenness is not reported as a crime in my data, so there is no direct comparison.

The results in Table 6 do not support the hypothesis that BIDs draw significant police attention. The top panel of Table 6 shows that Almost BIDs are most like BIDs in the distribution of arrest types, as they are the only comparison group to have more than 10 arrests for drunkenness annually. BID reporting districts have, on average, 15 such arrests.

The bottom panel of this table displays the coefficient on $\beta_{1}$ across the different estimation methods. Across methods, BIDs are consistently associated with significant declines in arrests for burglary. This should not be taken as a slackening of enforcement per se, as the number of burglary crimes also fell during this period in BIDs, as shown in earlier tables. Compare these results for burglary arrests with the rightmost columns, estimating BIDs' association with arrests for vehicle theft and drunkenness. Due to the LAPD's data categorization, arrests for vehicle theft cannot be compared directly with auto burglary and theft crimes. However, it is interesting to note that during a period in which auto burglary and theft falls significantly in BIDs, as shown previously, arrests for vehicle theft in BIDs remain virtually unchanged. Arrests for drunkenness, possibly the most discretionary of the 27 arrest categories, are little changed by BID adoption. Particularly when compared their closest counterparts in the Almost BIDs, BIDs do not show an increase in more discretionary arrests relative to less discretionary ones. I interpret these last two columns as suggestive evidence that any BID impact on enforcement is modest at best.

As a practical matter, BIDs should have a much easier time re-deploying existing resources than in getting the city to commit new ones. The detrimental effects of any small redistribution of municipal services are outweighed by the benefits, to BIDs and to the city, of the crime decline BIDs cause. 


\section{Further Specification Checks}

So far, the results have been remarkably consistent in associating BID adoption with crime decline, regardless of the estimation method chosen. This section implements a correction for possible serial correlation within a BID and then investigates whether the results are consistent with other predictions from the theory: that certain types of BIDs are more effective than others, and that certain types of crime should be more affected than others.

As shown by Bertrand et al. (2004) the difference-in-difference strategy may frequently identify an effect of a placebo policy in the presence of serial correlation. The difficulty with the author's recommended bootstrap correction is that it requires the knowledge of a "treated group" for the untreated. In my sample, BID groups are not defined for reporting districts that are never in BIDs. However, I can approximate such a treated group with my Almost BIDs sample. Resampling in the serious, less serious and total crime regression models, where the resampling cluster is either the BID and or Almost BID, I still reject the hypothesis that the coefficient of interest is equal to zero. ${ }^{50}$ This test clustering suggests that there is indeed some within-BID (or BID-like grouping) homogeneity in the error term, but that it does not invalidate the general thrust of the results.

In addition to this correction for serial correlation, I present two additional results consistent with the theory; the first of these deals with the heterogeneous effects of BIDs. Though I have been referring to BID members as property owners (and will continue to do so for convenience), the city of Los Angeles actually has both property- and merchant-based BIDs. Property based BIDs

\footnotetext{
${ }^{50}$ Similarly, clustering the standard errors at the BID or Almost BID level does not invalidate the main results. The standard errors on the three total crime figures - serious, less serious and overall - increase from 10.1 to $12.9,6.3$ to 6.7 , and 14.3 to 16.5 , respectively.
} 
assess property owners, run for a finite term, usually 3 to 5 years, and require a new vote to reestablish at the end of this term. Merchant-based BIDs assess business owners, and, after an initial vote, require a majority assessment-weighted protest to become inactive. In practice, neither type of BID has dis-established during my sample period, so both types of BIDs are not viewed as shortterm investments. Theory suggests that property owners should be willing to make larger investments in neighborhoods as they are the residual claimant to any successful investment. Though merchants also have an interest in improving their neighborhood, they are priced out if it is improved too much. The theoretical prediction of property BIDs' greater willingness to invest is borne out by their disproportionate share - 90 percent - of all BID investment, though property BIDs only account for 20 of the 30 BIDs in Los Angeles.

If property BIDs are willing to make more significant neighborhood investments, they should be more successful than merchant BIDs in lowering crime. This prediction is borne out in the left panel of Table 5. The first column of Table 5 repeats the coefficients from the estimation of BIDs on crime across specifications. The second two columns report the results from replacing the single BID dummy, BID $_{i}^{*}$ after $_{t}$, with two dummies - one for merchant BIDs and one for property BIDs. The results are striking in the consistency with which property BIDs account for a much larger share of the total decline in crime. In the fixed effects approach, property BIDs are associated with a roughly 12 percent decline in crime, while merchant BIDs are associated with an insignificant drop of 3 percent. This pattern holds across all estimation methods, and the minimum crime decline associated with property BIDs is 38 crimes, or 7 percent. These results are a good fit with the theoretical prediction that property owners should make larger investments and reap larger returns. To economists, the presence of merchant BIDs is something of a mystery, as merchant capture a much smaller portion of improvements in the neighborhood than property owners. 
Empirically, the behavior of merchant BIDs appears to take this into account - they make smaller investments and, after the end of my sample, are much more likely to dissolve.

Theory leaves an open door for BIDs' impact on crimes they do not seek to directly address. ${ }^{51}$ To test whether BIDs are associated with changes in crimes that they do not target, the right-hand panel of Table 5 presents results from two specifications - one where the outcome is all crimes a BID might be likely to affect, and one where the outcome is crimes that BIDs should be unlikely to directly affect. BIDs are likely to affect crimes such as robbery, theft, and assault. ${ }^{52}$ Crimes that BIDs are unlikely to affect are forgery (by far the largest contributor to the total), fraud, embezzlement, family crimes (domestic abuse) and non-prostitution sex crimes (i.e., child abuse). Across estimation strategies, BIDs are less likely to be associated with declines in this mix of unlikely crimes than they are with robbery. Of the six strategies, only 2 find an association between BIDs and the unlikely crimes.

\footnotetext{
${ }^{51}$ Broken windows advocates, led by Wilson and Kelling (1982), would argue that improvements in quality-of-life crimes would lead to improvements in all types of crimes.

${ }_{52}$ The full list is robbery, assault, burglary, auto burglary and theft, personal theft, other theft, auto theft, other assaults, vandalism, pimping, disorderly conduct and vagrancy.
} 
Table 4 BID Expenditures and Crime Decline

\begin{tabular}{lcccc}
\hline \hline & \multicolumn{2}{c}{ total crime change } & \multicolumn{2}{c}{ dollars per crime } \\
\cline { 2 - 4 } & as a function of BID budget in $\$ 1000 \mathrm{~s}$ & \multicolumn{2}{c}{3,226} & 1,220 \\
\hline Fixed Effects & -0.31 & -0.82 & & \\
& $0.06^{* *}$ & $0.15^{* *}$ & & \\
Almost BIDs & -0.27 & -0.74 & 3,704 & 1,351 \\
Matching & $0.06^{* *}$ & $0.16^{* *}$ & & \\
& -0.21 & -0.64 & 4,764 & 1,569 \\
Neighbors & $0.06^{* *}$ & $0.12^{* *}$ & & \\
& -0.27 & -0.72 & 3,667 & 1,385 \\
\hline \hline
\end{tabular}

* Significant at the $0.01 \%$ level. ** Significant at the $0.05 \%$ level.

Notes: Using the fixed effects approach, $\$ 1,000$ of total BID spending is associated with a reduction of 0.31 crimes, which translates to a cost of $\$ 3,226$ per crime. All regressions contain year fixed effects, area-level time trends, and reporting district fixed effects. Sample sizes are as reported in previous tables.

Standard errors are below coefficient estimates, and are clustered at the reporting district level

Source: Crime data from LAPD; BID information is author's tabulations from city documents. 
Table 5 Specification Checks

\begin{tabular}{|c|c|c|c|c|c|}
\hline \multicolumn{6}{|l|}{ Overall Means } \\
\hline & \multirow[b]{2}{*}{ total crime } & \multirow[b]{2}{*}{ merchant BIDs } & \multirow[b]{2}{*}{ property BIDs } & \multicolumn{2}{|c|}{ Should BIDs affect these crimes? } \\
\hline & & & & yes & no \\
\hline BIDs & 460.8 & 443.2 & 481.1 & 397.0 & 25.2 \\
\hline All non-BIDs & 316.6 & & & 270.7 & 15.9 \\
\hline Almost BIDs & 388.4 & & & 335.5 & 17.5 \\
\hline Neighbors & 313.8 & & & 269.6 & 16.3 \\
\hline \multicolumn{6}{|c|}{ Regression Results } \\
\hline & \multicolumn{3}{|c|}{ outcome is total crime } & \multicolumn{2}{|c|}{ Should BIDs affect these crimes? } \\
\hline & all BIDs & merchant BIDs & property BIDs & yes & no \\
\hline \multirow[t]{2}{*}{ Fixed Effects } & -51.05 & -20.10 & -67.89 & -48.77 & -5.16 \\
\hline & $11.10^{* *}$ & 12.13 & $15.46^{* *}$ & $10.21 * *$ & $2.23 *$ \\
\hline \multirow[t]{2}{*}{ Almost BIDs } & -41.98 & -12.22 & -55.11 & -35.88 & -4.58 \\
\hline & $14.31 * *$ & 16.02 & $17.01 * *$ & $12.96 * *$ & 3.38 \\
\hline \multirow[t]{2}{*}{ Matching } & -29.90 & -15.40 & -40.76 & -28.02 & -3.42 \\
\hline & $8.67 * *$ & 10.53 & $12.19 * *$ & $8.01 * *$ & 2.13 \\
\hline \multirow[t]{2}{*}{ Neighbors } & -43.35 & -20.32 & -54.20 & -41.65 & -4.75 \\
\hline & $12.00 * *$ & 12.13 & $16.26^{* *}$ & $10.73 * *$ & 2.53 \\
\hline
\end{tabular}

* Significant at the $0.01 \%$ level. ** Significant at the $0.05 \%$ level.

Notes: The first panel of this table reports coefficients from estimations of BID adoption on total crime, separated into the effects of merchant-based and property-based BIDs, showing that using the fixed effects approach, merchant BIDs are insignificantly associated with 20 fewer crimes per year, while property BIDs are significantly associated with 68 fewer crimes. The second panel separates total crime into two categories and separately regresses BID adoption on each. All regressions contain year fixed effects, area-level time trends, and reporting district fixed effects. Sample sizes are as reported in previous tables.

Standard errors are below coefficient estimates, and are clustered at the reporting district level.

Source: Crime data from LAPD; BID information is author's tabulations from city documents; property information is from the Los Angeles County Assessor via Dataquick software. 
Table 6 Measuring Police Enforcement

\begin{tabular}{|c|c|c|c|c|}
\hline \multicolumn{5}{|l|}{ Overall Means } \\
\hline & $\begin{array}{c}\text { number of } \\
\text { reporting districts }\end{array}$ & burglary & vehicle theft & drunkenness \\
\hline BIDs & 124 & 8.1 & 6.3 & 14.7 \\
\hline All non-BIDs & 885 & 5.2 & 5.4 & 6.9 \\
\hline Almost BIDs & 132 & 6.5 & 8.3 & 11.5 \\
\hline Neighbors & 291 & 5.2 & 4.8 & 7.0 \\
\hline \multicolumn{5}{|c|}{ Regression Results } \\
\hline & & \multicolumn{3}{|c|}{ arrests } \\
\hline & & burglary & vehicle theft & drunkenness \\
\hline \multirow{2}{*}{ Fixed Effects } & & -2.62 & -0.95 & 3.02 \\
\hline & & $0.67 * *$ & $0.39 *$ & 3.20 \\
\hline \multirow[t]{2}{*}{ Almost BIDs } & & -1.94 & -0.35 & -1.03 \\
\hline & & $0.82 *$ & 0.53 & 3.58 \\
\hline \multirow[t]{2}{*}{ Matching } & & -1.57 & -0.34 & -0.18 \\
\hline & & $0.45^{* *}$ & 0.30 & 2.18 \\
\hline \multirow[t]{2}{*}{ Neighbors } & & -2.02 & -0.68 & 2.18 \\
\hline & & $0.56 * *$ & 0.41 & 2.92 \\
\hline
\end{tabular}

* Significant at the $0.01 \%$ level. ** Significant at the $0.05 \%$ level.

Notes: Regressing BID adoption on the number of arrests by type, this table finds that, using the fixed effects approach, BIDs are associated with 2.6 fewer arrests for burglary and unchanged levels of arrests for vehicle theft and drunkenness. All regressions contain year fixed effects, area-level time trends, and reporting district fixed effects. Sample sizes are as reported in previous tables. Standard errors are below coefficient estimates, and are clustered at the reporting district level.

Source: Arrests data from LAPD; BID information is author's tabulations from city documents. 